ESRC Centre for Analysis of Risk and Regulation

The Invention of Operational Risk

Michael Power 


\title{
The invention of operational risk
}

\author{
Michael Power
}

\section{Contents}

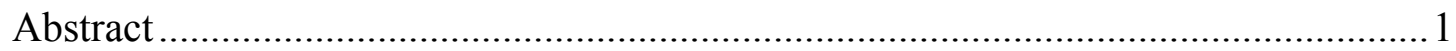

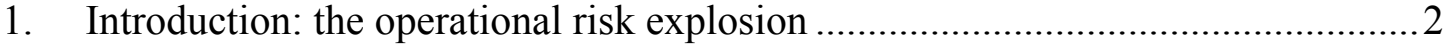

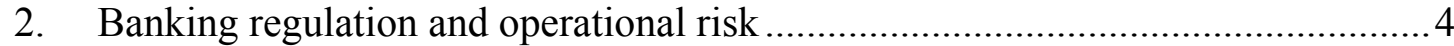

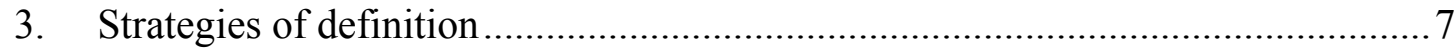

4. Risk identification and the contradictions of data collection................................

5. Quantification and trust in operational risk numbers....................................... 12

6. Hierarchies of calculation: measuring and managing ....................................... 14

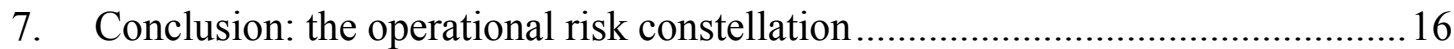


The support of the Economic and Social Research Council (ESRC) is gratefully acknowledged. The work was part of the programme of the ESRC Centre for Analysis of Risk and Regulation.

Published by the Centre for Analysis of Risk and Regulation at the London School of Economics and Political Science

Houghton Street

London WC2A 2AE

(C) London School of Economics and Political Science, 2003

ISBN 0753016524

All rights reserved.

No part of this publication may be reproduced, stored in a retrieval system, or transmitted, in any form or by any means, without the prior permission in writing of the publisher, nor be otherwise circulated in any form of binding or cover other than that in which it is published and without a similar condition including this condition being imposed on the subsequent purchaser.

Printed and bound by Printflow, June 2003. 


\title{
The invention of operational risk
}

\author{
Michael Power*
}

\begin{abstract}
Until the 'Basel 2' reforms to banking supervision, operational risk was largely a residual category for risks and uncertainties which were difficult to quantify, insure and manage in traditional ways. This paper examines the rapid emergence of operational risk from this low epistemic status to its institutionalisation as a key component of global banking regulation. However, the meaning and implications of the Basel proposals have been fiercely contested by international banks and three key domains of policy controversy have been, and remain, particularly visible: definitional issues, data collection and the limits of quantification. Tensions in these three areas are discussed and reveal the significance of operational risk as a meeting point for diverse concerns and interests, and as a potential reinvention of a management knowledge hybrid between auditing and finance. The paper draws attention to the ironies and contradictions of this operational risk programme, which is part of a visionary project to extend 'enforced self-regulation' deep into the operations of banking, combining advanced technical modelling ideas on the one hand and softer corporate governance thinking on the other. The Basel 2 proposals also demonstrate the policy effectiveness of 'operational risk' as an agenda-forming category, whose success lies as much in the catalytic visibility of the issue, as in the in the details of implementation.
\end{abstract}

\footnotetext{
* Michael Power is PD Leake Professor of Accounting and Co-Director, ESRC Centre for Analysis of Risk and Regulation. This paper was originally presented as the second of three PD Leake Trust lectures at the Säid Business School, University of Oxford, March 2002. Subsequent versions have been presented to the Department of Information Systems, LSE; the University of Alberta, Edmonton, Canada; the University of Warwick, UK, the University of Southampton, UK and the University of New South Wales, Australia.

The author is grateful for: the specific comments of Clive Briault, Julia Black, David Cooper, Yves Gendron, Wai Fong Chua, and John Thirlwell; for the financial support of the UK Economic and Social Research Council and the Trustees of the Institute of Chartered Accountants in England and Wales; and for the research assistance of Lea Clavecilla.
} 
Operational risk is not a new risk... However, the idea that operational risk management is a discipline with its own management structure, tools and processes... is new.

(British Bankers Association website, accessed 26.08.02).

\section{Introduction: the operational risk explosion}

Regulatory projects, especially those with global ambitions, are always in part visionary. By this it is meant that abstract possibilities and aspirations for control and order are articulated and projected via a myriad of discussion documents, codes of practice, guidance manuals and (sometimes) national law. In an initially ideal form it is easy for interested parties to find a space of general agreement about these projects, over and above the messy realities of, and negotiations about, implementation. Categories and systems of classification are important dimensions of this visionary process, providing both tentative maps for the reshaping of practice and new languages and ideas for agents of organisational change, particularly as practices become progressively more concrete and contentious.

Perhaps nowhere is this developmental process more evident than in the Basel 2 reforms of banking regulation and, in particular, the specific proposals by the Basel Committee on Banking Supervision for the management and regulation of operational risk. $^{1} \quad$ The process of developing, implementing and supervising operational risk management in banks is evolving and incomplete, and at the time of writing, the third consultation paper has been published (Basel Committee on Banking Supervision, 2003a). However, in many respects the most difficult and decisive step has already been taken: the rise and institutionalisation of 'operational risk' as a category of regulatory and managerial attention. This paper addresses three related dimensions of this process of institutionalisation, and explores the tensions and interests at stake in the emergence and normalisation of practice in its name.

To suggest that operational risk has been 'invented' is not merely figurative or fanciful. Of course, businesses in general and banks in particular have been aware for many years of hazards and uncertainties arising from information technology (IT) infrastructure, human motivation and fraud, business disruption, legal liability and many similar issues. However, the renewed visibility of these risks under the label of 'operational risk' re-positions their location and status for management decisionmaking purposes. Furthermore, Basel 2 make connections between the management of operational risk and good corporate governance in such a way as to position these 'old' risks in a new space of regulatory, political and social expectations.

The generic term 'operations risk' had already been officially coined in 1991 (COSO, 1991) but did not acquire widespread currency until the mid to late 1990s when the Basel 2 proposals were developed and published in June 1999. In retrospect, it is tempting to regard Nicholas Leeson, the 'rogue' trader attributed with the destruction of Barings bank in 1995, as the true author and unwitting inventor of 'operational risk'. But it is more accurate to say that Barings (and other scandals, such as Daiwa) was marshalled to construct a 'history' of operational risk, and to serve as a paradigm

\footnotetext{
${ }^{1}$ The proposals and related materials can be accessed at the Basel Committee website at www.bis.org
} 
example of operational risk failure within a regulatory discussion that was already well underway. At the level of industry mythology, Leeson did for operational risk what Robert Maxwell did for corporate governance; both are part of the iconography of regulatory failure. But, in reality, the Basel Committee on Banking Supervision within the Bank for International Settlements (BIS) was already looking afresh at the scope of the existing 1988 guidance. Thus, it is more accurate to say that the stripping out of 'operational risk' as a discrete category by Basel 2 in fact made possible the retrospective writing of case histories of Barings, Daiwa and others failures in terms of that category.

If 'operational risk' scarcely existed as a category of practitioner thinking in the early 1990 s, by the end of the decade, banking regulators and practitioners could talk of little else. ${ }^{2}$ Books were being published, conferences were being organised, and apparently new roles, such as 'operational risk manager', were being created; there was even talk of an 'operational risk' profession. Operational risk in the banking industry started life as a residual category, something left over from market and credit risk management practices, a fear category with a problematic reality and status. For this reason, it has proved problematic to define, although such difficulties in fixing meaning have enhanced, rather than detracted from, its importance. Operational risk is therefore no simple or self-evident category; it is a label for a diverse range of practices, a vision of control and regulation in an elusive field, and an imperative to manage a newly visible range of problems. It is both a name for a set of problems and interests, and a promise of a new way of intervening in the internal structure of financial organisations.

The emerging 'operational risk' management agenda is necessarily grafted on to the existing technical agendas of different occupational groups. For example, in June 2001 , the $4^{\text {th }}$ Annual Global Financial Industry Forum could address the topic of 'Managing operational risk and latest developments in achieving operations, settlements and payments efficiencies', thereby constructing the concept of operational risk in the setting of very specific and longstanding interests in settlement systems, by an established community of credit risk managers. ${ }^{3}$ So, far from simply describing a given field of expertise, the demand for operational risk also problematises expertise and is constructed in the shadow of existing communities of practice who must translate their concerns into its language. In this respect, the answer to the question: 'What is operational risk?' cannot be separated from the question: 'Who is reinventing themselves in the name of operational risk?' Operational risk and the Basel 2 reforms create a new competitive space for various control agents inside financial organisations, who re-launch what they do in the name of operational risk management. For example, the parallel emergence of 'legal risk' as a sub-set of operational risk has provided a platform for the reinvention of legal advisory work within organisations.

\footnotetext{
${ }^{2}$ In 2000 the Risk Waters group began to publish a weekly newsletter with that title.

${ }^{3}$ This series of conferences started in 1998 and while the Basel 2 reforms are not the only point of reference in the proceedings, it is clear that they cast a shadow over the entire event. Such conferences act as important platforms for knowledge leadership and promotion by consultants offering masterclasses and similar packages. Ernst \& Young, one of the sponsors of the event, have been active in positioning themselves in the advisory market for operational risk related services (eg, Ernst \& Young, 2001).
} 
The discussion that follows is not intended to offer any kind of preferred definition of 'operational risk'. Rather the objective is to track different attempts to fix the meaning of operational risk, and to constitute forms of data-gathering practice, supporting forms of economic calculation in its name. This essay is therefore concerned more with mapping a 'logic of practice' (Bourdieu, 1992) in the making, rather than addressing detailed technical discussions of modelling operational risk. The analysis is concerned to locate three fracture points in a specific programme in Rose and Miller's (1992) sense and focuses primarily on the policy level discourses of the banking 'risk regulation regime' (Hood et al, 2001).

The next section provides a descriptive overview of the Basel 2 proposals regarding operational risk and their significance for banking regulation. This is followed by three sections dealing respectively with: the problem of defining operational risk, data collection and quantification. All three areas reveal tensions in the logic of operational risk, ie, between broad and narrow definitions, between routine and non-routine data and between hard and soft philosophies of quantification. The final section provides a critical discussion of these tensions in the context of competitive pressures in the hierarchy of management knowledge.

\section{Banking regulation and operational risk}

Banking regulation has evolved over the years in the shadow of crisis (eg, Moran, 1986, 1989). In 1974, a 'club' of central bankers, the Basel Committee on Banking Supervision, was formed to create a global policy body for banking supervision. The committee has national regulatory authority per se, but has de facto power via the implementation of its recommendations by national supervisory bodies. The committee is located in, and administered via, the Bank for International Settlements and in 1988 devised a system for regulating the adequacy of the capital base in banks.

This capital charging process is part of the deep logic of banking regulation, and the intention has always been to provide, in the case of individual banks, a buffer adequate to cover unexpected losses relative to the risks undertaken by the banks themselves. In addition, such a buffer, by acting to prevent banking failure at the individual bank level, simultaneously reduces to acceptable level the 'systemic' risk, ie, the risk that a failure of a single institution could create failures elsewhere in the system because of the interconnectedness of transactions and institutions.

The original thinking behind the capital charge as a safety buffer is already inherent in the generic concept of capital in company law, and also emerges from, and formalises, the specific practices of banks' reserving policies. However, this process of regulatory induction in designing the 1988 Accord, which is very common in 'kickstarting' regulatory arrangements so that they can command legitimacy and consent, was not risk-sensitive (Vieten, 1996). For many banks in the 1980s therefore, the new regulations simply endorsed and formalised a high level average of what they did anyway, and the ratio of eight per cent capital to assets became a minimum benchmark with no other rationale than that it seemed to correspond broadly to what was already done (with the exception of Japan where the historic ratios tended to be lower); de facto practice always leads 'best' practice. 
The capital charge was determined by a banking supervisor, usually but not always the central bank, and was calculated on the basis of disclosed balance sheet items weighted according to judgements about their underlying risks. Over time, banks began to complain about the calculative basis of the charge, arguing that it was arbitrary and did not discriminate sufficiently between the different risk profiles of specific banks, or between different risks within a single bank. Banks who felt that their risk management processes were good believed that the regulation placed them at a competitive disadvantage in requiring too much capital to be maintained.

The Basel Committee was influenced by these views and began to develop a new strategy, recognising for the first time the calculation of regulatory capital based in part on the risk models and systems of the banks themselves. In this respect, one can discern a significant shift, at least at the level of formal policy, from a broadly command-and-control style of banking supervision to one more consistent with ideas of 'enforced self-regulation' (Ayres and Braithwaite, 1992) in which banks are still required to regulate capital, but according to their own models. The major change in this direction was implemented in 1996, when the Basel Committee rules permitted the use of in-house models for the purpose of reserving capital against market risk exposure. This made good sense, since bank modelling techniques were most advanced in the area of market risk, ie, the risk to portfolios of assets arising from changes in underlying market variables. In addition, it is in the nature of these models that their quality can be rigorously back-tested. Thus, in the case of market risk, models could almost entirely replace regulatory discretion (although they can be subject to an arbitrary 'multiplier'), but in other cases, the uses of risk-sensitive proprietary approaches remains subject to considerable regulatory determination.

In general, it became accepted that regulatory moral hazard, whereby individual banks are better placed than regulators to understand their exposures, could be ameliorated by nurturing self-interest in ensuring a capital reserve appropriate to risk exposures. This is the broad underlying philosophy of Basel 2, a system which assumes that banks' risk appetites can be more or less aligned with those of regulators, and that therefore it is generally efficient to leave the detail of regulation to the banks themselves, subject to monitoring, backtesting and multipliers.

Another strand of regulatory thinking is distinct from the capital charge requirement ('Pillar 1') and relates to more general internal risk management and control practices ('Pillar 2'). This strand has always been considered to be important in the management and regulation of banks, although being less amenable to quantification has appeared more humble and less glamorous. The need for internal control systems has been a part of banking legislation since the 1980s (eg, the UK Banking Act 1987, s 39) but over time, as the self-management of risk for banks has become more significant, supervisory systems and approaches were re-designed to take account of a new accent on internal control (Basel Committee on Banking Supervision, 1998a). In particular, there is a tradition of setting capital levels in excess of the regulatory minimum to reflect judgements about a bank's control environment. More recently, a threshold standard for internal control is required as a necessary condition of using advanced approaches for calculating capital. 
Taking the capital charge and internal control strands of supervisory practice together, the role of the supervisor is itself reconstructed as a 'risk manager' overseeing the models (Pillar 1) and systems (Pillar 2) used by banks. It is within this emerging climate and style of regulation, that the problem of operational risk has emerged. The new Basel capital accord (Basel 2) represents an evolution of the capital rules for banks, extending and refining the basic idea of a capital cushion for risks, both measured (credit and market) and non-measured (which, perhaps only in hindsight, could be argued to be implicitly covered by the 1988 accord) (See Basel Committee on Banking Supervision, 2003a). Non-measured risks became a more conspicuous supervisory issue and came to be problematised in terms of 'operational risk' management. The category became increasingly institutionalised from 1998 onwards. ${ }^{4}$

The new capital accord has three main components which overlap; as indicated above, the first 'pillar' sets minimum capital standards and embodies both qualitative and quantitative requirements for risk management. The debate about operational risk assessment and measurement is at its sharpest in this context. The second pillar concerns the adequacy of the control environment and systems, and the third concerns the nature and extent of bank disclosures about the process used to manage and control risk.

As far as the first pillar is concerned, where the measurement of operational risk capital is central, the regulatory approach adopted is evolutionary in vision. Banks are encouraged to develop their approaches to operational risk management along a oneway, increasingly risk-sensitive continuum from a basic to a standardised and ultimately to a sophisticated, 'advanced', internal measurement system. Once a bank qualifies to use a more sophisticated approach, it becomes mandatory for it to do so. In order to encourage this evolutionary process, Basel 2 originally set 20 per cent of current minimum regulatory capital as an opening benchmark for the new operational risk (OR) capital charge, a ratio derived from observed practice. This was subsequently reduced to 12 per cent, and the original details of the standardised and advanced measurement approaches have been modified.

The process of developing these rules for measuring operational risk capital has been, and remains, subject to considerable industry negotiation, featuring 'road shows' and marketing of best practice by the Basel Committee (eg, Basel Committee on Banking Supervision, 2001b) staff. At the time of writing, Basel 2 will be implemented in 2007 and the results of the third quantitative study in late 2002, essentially a dry run, have been published (Basel Committee on Banking Supervision, 2003b). ${ }^{5}$ Standing

\footnotetext{
4 Indicative evidence for this is provided by a non-systematic sample of ten major banks' annual reports in Australia, France, Germany, UK and USA. These reports show the first mention of operational risk as a narrative disclosure category from 1998 onwards, with only two mentioning the concept prior to this.

5 QIS3 has dual objectives: first to ensure that total capital in the banking system remains stable ('broadly neutral') under the new regime; second to monitor the incentive for banks to use the more advanced approaches, ie, whether a lower charge is forthcoming at the individual bank level. Given the apparently contradictory nature of these objectives, it is worth bearing in mind Goodhart's criticism that: 'the new emphasis on operational risk is partly just a smokescreen for a cumulative add-on factor, to offset the reduction that would
} 
back from the extensive detail of the proposals, the ambition of this supervisory project of control may be without precedent in its attempt to reach into the micromanagerial world of banks. Half the banks in an early survey (Basel Committee on Banking Supervision, 1998b) had created an operational risk manager independent of the business lines, eg, the Royal Bank of Scotland where a Head of Group Operational Risk (subsequently a Head of Group Enterprise Risk) reports to the Director of Group Risk, alongside the heads of credit and market risk. This reflects a growing corporate determination to manage operational risk as an internal reality, rather than just as a matter of regulatory compliance (see also BBA, ISDA and RMA, 1999).

There can be no doubting the ambitious nature of the Basel 2 proposals with respect to operational risk. Certain issues or clusters of issues are controversial hotspots, in part because they stretch the logic of the capital cushion, a deep part of bank regulatory thinking, to its very limit. ${ }^{6}$ In the next section, the first of three hotspots is considered; the problem of defining operational risk itself. In subsequent sections, the controversies surrounding data collection and quantification will be addressed.

\section{Strategies of definition}

Definitions matter not just in providing agreed meanings for practitioners; they also delimit the jurisdiction of practices in the system of professional knowledge (cf. Abbott, 1988), even functioning to constitute economic life in new ways (Tribe, 1978). So, the project of defining operational risk is more than a simple matter of labelling, and is a meeting point for different interests and ambitions. In its early manifestations, operational risk was simply a residual category for 'other risks' not covered by market risk and credit risk. Hence, the re-diagnosis of some large losses as operational risk failures simultaneously challenged the low epistemic status of this residual, and with it the related professional and regulatory order in the banking world. Throughout the 1990s onwards, relatively low status functionaries, such as internal auditors, began to have a voice in the name of operational risk that they could not have dreamed of in the 1980s. From the mid-1990s, a project of positively defining and determining 'operational risk' was coextensive with establishing new boundaries of knowledge and practice within financial organisations. And yet, this was a project fraught with a single serious difficulty: operational risk is 'extremely hard to define' (Goodhart, 2001).

In March 1997, a joint survey by the British Bankers Association and Coopers \& Lybrand explored several definitions. Drawing on BBA, ISDA and RMA (1999), Basel 2 eventually defined operational risk as 'the risk of direct or indirect loss resulting from inadequate or failed internal processes, people and systems or from external events.' (Basel Committee on Banking Supervision, 2001a, para 6). This

otherwise occur from the move towards more sophisticated measurement of the other kinds of risk.' (Goodhart, 2001: 14). In addition to QIS3, there was also an Operational Risk Loss Gathering exercise.

${ }^{6}$ For example, there has been discussion about the conservativism of rules which don't take diversification benefits or beneficial non-operational risks into account. Basel 2 opens a Pandora's box whereby banks lobby for lower capital charges on the basis of a variety of idiosyncratic risk management practices. 
definition, which reflects a long process of discussion and debate, was clarified to exclude reputational and strategic risks, and focuses on causes of loss. The definition also reflects a negative view of risk as downside loss, rather than of simple variability of outcome around an expected mean (eg, Gigerenzer, 2002: 26).

Definitional options for operational risk are strategically significant: as the definition becomes broader and encompasses more potential sources of loss, operational risk management moves beyond the ambit of any existing departmentally-based risk manager, and potentially involves greater organisational change and 'lots of stepping on toes' (Jameson, 2001a). On the one hand, systems failures and payment errors can be laid at the door of those technical operatives responsible for these systems. On the other hand, the unauthorised trading and cover-ups which occurred at Daiwa and Barings in 1995 reflect a failure of senior management oversight. Indeed, this shows that the concept of operational risk varies in its significance for management hierarchies. Without doubt, Basel 2 is a project of repositioning the responsibility of senior management for managing different parts of the operational risk 'jigsaw'. These senior management ownership issues are part of a broader climate, a 'new risk management' (Power, 2000) being expressed in terms of enterprise risk management (ERM) and merging the discourses of corporate governance and of banking supervision. The problem of defining operational risk for banks lies at the very heart of these transformations, and has provided opportunities for internal agents, such as lawyers and accountants, to redefine their work in terms of risk management.

The work of Douglas (1992) suggests that operational risk is necessarily a forensic category and that therefore any definition of operational risk is driven in part by what it is sensible to blame a single middle level manager, as compared with the Chief Executive Officer (CEO). It makes no sense to blame someone whose expertise lies in information security or human resource management for bad marketing or poor public relations, for being uncompetitive or for changes in tax laws. In short, the definition of operational risk embodies and reflects varying intuitions about the difference between functions and responsibilities which are properly senior and strategic, and those which are not. It also reflects intuitions about the nature of 'losses' and 'errors' which are relevant to operational risk. Some banks, with a wider definition of operational risk, do not see the need for a separate operational risk function, although this is likely to change in response to regulatory requirements. Others, for whom a narrow definition reflects a focus on internal control systems, do. Accordingly, definitions, responsibilities, concepts of error and of loss, and potential risk management jurisdictions are mutually constitutive.

It has been argued that the accountants' concept of internal control is the starting point for thinking about operational risk management as an integrating function (Wilson, 2001). Accordingly, defining operational risk is fundamentally different from defining market or credit risk as discrete functional areas; the definition of operational risk matters as a basis for connecting disparate functional areas and is thereby inevitably political. As operational risk management is defined in a more inclusive manner, it assumes a higher order monitoring status location than is apparent from Basel 2. For example, stress testing market risk models is part of market risk management, but failure to stress test market risk models against extreme market movements (allegedly in the case of Long Term Capital Management) is a form of operational risk. From this point of view, far from being a residual, operational risk 
management could be said to oversee the organisational environment of market and credit risk management.

To summarise: strategies of defining operational risk are necessary conditions for an emerging discipline of operational risk, which is becoming more than the sum of its established constituents such as settlement systems. Definitional work is undertaken by organisational agents who construct new practices around concepts, protocols and related interpretations of risk phenomena. Definitions of key concepts are an intimate and central part of the logic of any practice; without a system of concepts and taxonomies, any practice of intervention is blind, disorganised and of questionable legitimacy. Definitions are also attention-directing devices and strategies which determine objects of managerial and regulatory interest, objects which in a very real sense are vague and ambivalent at the edges but which become determinate through the processes of intervention and control conceived in their name. In this sense definitions can 'kick-start' practices and to a large extent Basel 2, and its evolutionary philosophy, has been very successful in doing this. Despite controversy over meaning and implementation, operational risk management has been firmly established by Basel 2 as a component of banking management strategy. However, definitions and related categories of relevance are also only realised and instantiated by specific datagathering exercises in their name, and it is to this aspect of the construction of operational risk management that we now turn.

\section{Risk identification and the contradictions of data collection}

The category of operational risk is significant not merely as an assembly point for existing risk management practices, but also as a category of attention and visibility for risks/threats which were either ignored by banks, or made insufficiently explicit in management systems. From this point of view, operation risk is part of a broader shift in awareness about the importance of the completeness of risk identification for any risk management system, of getting issues onto the agenda of management thinking. However, a crucial phase in the realisation of management practice is data collection. At this point, 'dangers' become 'risks' capable of being located in the logic of managerial decisions making (cf, Luhmann, 1992) and in a business/management model which supports routine data collection.

The data collection debate is in essence a reformulation of the definitional discussion, and has similar strategic implications. What data are relevant to operational risk and its management? Historic losses for the organisation? For the industry? At the heart of the operational risk debate is a discussion about the meaning of 'expected loss'. Are expected losses effectively covered by accounting provisions, leaving unexpected losses to be covered by the capital cushion? And what of sudden catastrophic events? Are they to be prevented by internal controls, or possibly transferred by insurance, or is there nothing to be done here but to mitigate via business continuity plans? Are potential losses relevant too, such as compliance errors and related near-miss events? As the Basel Committee recognises, 'there is often a high degree of ambiguity inherent in the process of categorizing losses and costs' (Basel Committee on Banking Supervision, 2001a, para 8) and as Vaughan (2002) suggests, how organisations define and then 'cleanse' errors are part of its rituals of managing. In the case of Barings, internal control weaknesses could not be defined ex-ante as anomalous by 
the organisation itself. The collapse also showed that certain risks can cross existing conceptual boundaries (Cagan, 2001), boundaries which correspond to distinct levels of management process.

The definition of error always takes an institutional form. For example, the entire capital charging structure underpinning Basel 2 is weighted towards the recognition of concrete ex-post events, direct losses and write downs. Anticipatory and preventative investments in internal controls are valued in so far as they impact on the future loss experience of the bank. Although, Basel 2 seeks to nurture experimentation in the operational risk area, practitioners in the 1990s and early 2000s have been uneasy about this deep logic in their thinking, an unease compounded by the ambivalent relation between existing accounting systems, designed for actual and expected losses at best, and the potentially broader scope of operational risk relevant loss events, to include unexpected losses and 'near misses'. Databases are also argued to be 'shaky and fragile' (Goodhart, 2001) not just because of these definitional ambiguities, but also because significant single event operational losses are rare.

The capital charge for operational risk should, in theory, reflect the experience and risk profile of a bank but the Basel Committee in its early studies also admitted that the current state of knowledge and loss data was so poor that the internal measurement of operational risk is 'still in the dark'. Appropriate data is absent for all but a handful of banks, and industry standards for such data are still lacking (Cagan, 2001). As the Basel Committee on Banking Supervision (1998b) report acknowledges, following a survey of practice in 30 banks, large loss experiences are rare and adequate time series for operational losses and their causes do not yet exist. Hence there is, almost by definition, data poverty where it is most needed for heterogeneous catastrophic events and, except for a range of normal errors, eg, transactions processing, firm-specific data is generally inadequate.

In short, data for operational risk management is most needed where it is both thin and conceptually problematic, ie, for rare, high impact possibilities. It is also unclear how any database for losses of these kinds is coupled to the internal control environment since serious operational risk events may not be linked to transactions in a clear way. In early discussions of Basel 2, banking practitioners have argued that it is problematic to use historical loss data for calculating economic capital, if controls are always improved in the light of loss experiences. In addition, it is not always clear that loss data is valuable since it is often silent on causation. More critically, the probability measure component of the capital calculation is not a given based on frequency data, but can be influenced by management; probability in these settings is space for social action and is behavioural (Wynne, 2003) or performative (Mackenzie, 2002) in form, rather than technical. ${ }^{7}$ Demonstrable adherence to corporate governance standards under pillar 2, such as those prescribed in the UK by the Turnbull report (ICAEW, 1999) should lead, in theory, to an adjustment factor by the Basel regulations, especially as good controls are a prerequisite for the use of advanced approaches. The Committee has been initially hesitant to develop explicit scores for internal controls because they may not be 'objective', arguing that good internal control translates into lower loss experience in later years. In this way,

\footnotetext{
${ }^{7}$ According to John Thirlwell (private correspondence with the author), 'operational risk is a social rather than a mathematical science'.
} 
although banks have historically been required to have higher minimum capital where controls are judged to be weak, banks with good controls are more likely to get credit ex-post only via lower loss experiences and by being permitted to use advanced measurement approaches (AMA).

Another behavioural dimension of the data collection issue relates to incentives. There can be disincentives to report relevant events if they are likely to increase the capital charge to the business unit. For example, while internal agents such as inhouse lawyers and human resource specialists may have no disincentive to report near misses (because they enhance their own role), operational departments may wish to hide these events, or translate them into credit and market risk issues. Equally, risks and losses may be reported and overstated as part of an argument to secure more resources. At its worst, data collection methods used 'in order to limit the adverse effects of an event, may result in incentives which would increase the number of such events themselves' (Goodhart, 2001: 12), making data collection a perverse form of 'fatal remedy' (Sieber, 1981) for banks.

The data collection problematic has further consequences for the debate about the role of insurance. Some critics argue that Basel 2 overstates the applicability of the capital cushion philosophy, when insurance and internal process controls should do the job of risk management as well (eg, Calomiris and Herring, 2002). Some banks argue that insurance is part of the overall risk management process and that the focus of capital adequacy should be on residual risks after insurance. However, while there is some allowance for insurance under AMAs, supervisors are cautious for systemic risk reasons: operational risk management could be handed to an insurance market which it considers to be under-capitalised. In addition, one large loss on an operational risk policy could eradicate the market for cover. But the deeper question is about the actuarial base for operational risk insurance given the problems of data definition and frequency discussed above (Goodhart, 2001). There may be no rational basis for correlating premiums and risk, and questions exist about the scope of policies and how claims might be paid. Indeed, insurance policies can have many idiosyncratic features (deductibles, limits, etc) which make them difficult to value.

Two 'solution paths' to the data collection problem have emerged, one more selfconscious than the other. The first path consists of solving the infrequency problem by pooling loss data across banks to generate richer databases. To this end, new pooling institutions have been created, such as the BBA operational risk database association in the UK, to share loss data with the aim of improving operational risk information at the industry level. The development of these databases to pool loss experiences encounters the persistent problem of confidentiality and proprietorial advantage, rather as the mortality tables of the nineteenth century were proprietorial assets for life insurance businesses. But even if these approaches become established, they have the effect of making an internal approach to operational risk measurement de facto external, thereby blunting the risk-sensitivity to specific organisations, which is the whole purpose of the advanced approach. So pooling of loss data is one potentially self-contradictory 'solution' path.

The other, less conscious, path follows from the extensive evidence that organisations tend to collect the data that they can, given legacy information systems, rather than the data they need. There is some evidence in relation to operational risk, that banks 
are using databases for medium frequency, low to medium impact losses, partly because this is what can be done to make quantitative modelling possible. This is the point at which the tail of data collection may wag the dog of operational risk management, suggesting that organisations construct notions of error and its management which fit existing institutionalised patterns of information gathering, while other significant anomalies may go unnoticed (Vaughan, 2002). However, despite the myths of Barings and Daiwa type events, it is also clear that the operational risk management agenda has focused bank attention on medium to high probability events with low individual impact, but which in aggregate may yield significant losses. Fines for mis-selling financial products, recent fines imposed on some US investment banks, and credit card fraud losses have also given the operational risk management agenda a non-Barings flavour, with a strong emphasis on legal liability risk and fraud prevention.

In summary, operational risk management is far from being a simple technocratic process involving risk identification and data collection. Data collection is a constitutive and performative process, which identifies organisational categories of error, mistake and anomaly, and locates them as risks for decision-making purposes. Data collection is also a behavioural challenge to 'buy-in' by banking staff and to the organisational capacity to use 'new' data sets to challenge prevailing cultures and norms. Operational risk management is faced with a potential puzzle. On the one hand, as an emergent managerial and supervisory category it is dramatised by the historical experience of low probability, high impact events, ie, the rogue trader paradigm. On the other hand, the practice of operational risk management is being shaped by existing patterns of risk management working by internal agents in relation to medium to low impact and medium to high probability events. These agents, such as lawyers and internal auditors, define the operational risk agenda in their own terms. Organisations collect the data that these agents consider to be relevant to working practices, and construct notions of error which can be operationalised but which may not correspond to an originally defined need. And, in part, these data collection activities are also driven by the imperative of quantitative modelling of operational risk, an institutionalised trust in measuring that we now discuss.

\section{Quantification and trust in operational risk numbers}

'... operational risk measurement is not the same as operational risk management. Quantifying those operational risks that lend themselves to quantification and neglecting the rest does not constitute best practice...' (Cagan, 2001).

The rise of operational risk management reveals different forms of 'trust in numbers' (Porter, 1994) for management purposes. There are varied aspirations to measure in the shadow of the benchmarks provided by the institutional legacy of credit risk and market risk modelling. Demands for 'robustness' are conspicuous. Some commentators refer wistfully to the 'immature' nature of risk modelling for operational risk and bemoan the fact that there is no alternative to 'semi-quantitative' methods (eg, Wilson, 1995). Pressures for an ideal rational economic basis for capital charging exist even when so-called softer approaches are used for practical reasons. The method of the risk adjusted rate of return on capital (RAROC), though not peculiar to the operational risk debate, is instructive. 
The idea behind RAROC is that it adjusts profit of a unit for capital at risk (Jorion, 2001: 96) and computes a rate of return on economic capital staked. It presupposes the quantification of capital at risk, and this then allows the performance of different units/traders to be compared as a reward to risk capital ratio. Interest in RAROC grew as a consequence of dissatisfaction with regulatory risk ratios. For many banks, the search for 'true economic risk', or at least better representations of risk than arbitrary regulatory adjustments, was part of the search for improved performance measurement and a continuing critique of regulatory practice, pressures which led in part to the adoption of in-house models in 1996 for market risk purposes.

This adversarial environment led to a rash of conferences/concept papers on RAROC in the early 1990s, culminating in the demand for a more 'rigorous' RAROC practice which 'feeds off a bank's underlying risk models and data' 8 RAROC represents a programme, an ideal of aligning regulatory objectives for safety via a capital cushion and managerial objectives for efficient allocation of resources and performance appraisal. RAROC is therefore the enforced self-regulation ideal.

Theoretically, RAROC represents a win-win convergence of regulatory and economic capital, 'but if line managers can't understand the approach... RAROC can't gain acceptance across a bank,' (Jameson, 2001a). Managers must become 'comfortable' with capital allocations based on RAROC: 'This is partly a problem of bank politics and balance: making sure that senior managers support RAROC projects, that business lines are involved and that RAROC figures are neither rejected out of hand nor used uncritically.'(Jameson, 2001a: 5). So, whatever the technical merits of RAROC as an integrative risk measurement technology, it is part of a complex organisational politics, one potential tool among others in pricing decisions. This suggests that, while RAROC provides a climate for decision-making and a language for risk management investments, there is more of a looseness of fit with the way RAROC calculations are used and behavioural issues are as critical as technical ones: '...while it is important to get the formula right, RAROC analyses are part of a longer term battle for the hearts and minds in an institution' (Jameson, 2001a).

The idea that rational calculation must be 'sold' to practitioners is not new; studies of new accounting systems demonstrate the complex micro-politics of accounting change. Furthermore, the implementation of RAROC-based systems changes power relations in banking organisations, just as divisional performance measurement has done more generally. RAROC is about new centres of calculation which shift power to different experts in organisations, armed with data and the authority to interpret. According to the head of group risk at SEB, a Swedish bank, the internal motivation for RAROC is to produce better pricing of banking products, especially in areas where market prices do not really exist, and discipline over 'capital hungry' units. In this sense, RAROC is part of a project of creating and constituting economic markets in specific financial products (cf Mackenzie, 2002). It is a descriptive, but also a critical and constitutive tool.

\footnotetext{
8 Jameson (2001a) bases his comments on interviews with: Anders Kragsterman, Head of Group Risk Control, Skandinaviska Ensckilda Banken (SEB); Russell Playford, Wachovia Corporation; Tom Wilson, Chief Risk Officer, Swiss Re New Markets, New York.
} 
According to Jameson (2001a), practitioners accept RAROC as a general philosophy or ideal, but it is not yet realised as a 'true risk metric', and the conceptual battles are not over. While there is pressure to iron out 'technical wrinkles, it is also accepted that it is 'difficult to build some factors, such as the long-term value of a customer relationship, into the model' and that an attractive RAROC figure is not an automatic green light to expansion of a business line. These qualifications to the RAROC project of rational calculation explain why internal discussions 'can degenerate into political skirmishes'.

To summarise: RAROC is at the heart of an ambition for 'rational' capital charging as a micro-level discipline over banking lines of business. Experiments with RAROC as a generic technology predate Basel 2, but this is the idealised model against which the rational management of operational risk and the allocation of operational risk capital is judged. Despite a clear theoretical specification, RAROC has a certain operational indeterminacy as a technology of calculation, not least because of the data collection ironies discussed in the previous section. While it may provide a common economic language for supervisors of, and managers in, banks, there are nevertheless important tensions and difficulties in the idea and practice of RAROC, tensions which the case of operational risk management brings into sharp relief. These tensions can be articulated as a problem of 'hierarchies of calculation' and of degrees of trust in numbers.

\section{Hierarchies of calculation: measuring and managing}

Practitioner discussions and commentary on Basel 2 suggest two hypothetical idealtypical approaches to operational risk, which reveal varying alliances to ideals of measurement and management:

1. The first approach is that of calculative pragmatism. Adherents typically regard numbers as attention-directing devices with no intrinsic claims to represent reality. Risk scoring systems make risk capital visible for management purposes and help to steer behaviour in the right direction. Operational risk demands a pluralistic management and is more akin to a craft than a science. Core knowledge is based in the disciplines of audit, credit control and systems management, process and human resource management.

2. The second approach is that of calculative idealism. Adherents typically regard numbers as aiming to represent the costs of true economic capital based on high quality frequency data, and inducing correct economic behaviour in the light of these risk measures. Operational risk must be made to fit a knowledge paradigm in which techniques of value at risk measurement are central and in which the discipline of market risk management is the benchmark. While practitioners under this approach may be short-term pragmatists, they have a reductivist, non-pluralist view of operational risk management and worry constantly about the 'robust' and 'hard' nature of operational risk analysis.

These two contrasting styles of approach to operational risk represent competing 'logics of practice', both of which are represented in the Basel 2 proposals. 
A good generic example of calculative pragmatism is Simons' (1999) risk calculator technology, a tool which generates qualitative scores for the riskiness of different functional areas. The tool generates scores which are performative and become objective by virtue of being used by management and by virtue of being attentiondirecting. The process has nothing to do with measuring risk in terms of frequencies and even little connection with a process of measuring subjective 'degrees of belief' (Gigerenzer, 2001: 26-27). However, Simon admits that 'the risk exposure calculator is not a precise tool...' and its results are 'directional' only (Simon, 1999: 86).

Calculative pragmatism of this kind, commonly referred to as 'soft' risk management, makes sense in environments where it is critical to identify and catalogue risks which lie at the limits of formal knowledge, hence its importance in the emergence of operational risk management. Scoring systems which emerge from consultative, focus group processes make risk identification and mapping a semi-expert practice which presupposes a 'knowledge and wisdom base in all organisations that can provide powerful feedback for the purposes of mapping risks' (Cagan, 2001). For example, Bankers Trust, identified by Jorion (2001) as a 'pioneer in risk management' (Jorion, 2001: 96), allocated capital to operational risk relevant activities based on identifying risk information categories and scoring for a range of factors including inherent risk, control risk and actual loss experience (Hoffman, 2002; Wilson, 1995). In another experiment, the chief risk officer at ANZ bank, Mark Lawrence, used a similar scorecard system, claiming it was a forward-looking and rational basis for allocating economic capital to business units (Jameson, 2001b). For calculative pragmatists, scoring systems for economic capital which generate crude but directionally effective RAROC numbers have the behavioural merit of reminding line managers about the cost of capital.

But while there may be some agreement about the merits of doing something rather than nothing, calculative pragmatists can be distinguished from calculative idealists by their resistance to a perceived reductionism in Basel 2 and the conceptual dominance of the capital cushion ideal. For them, internal control systems rather than calculations of capital have priority in the management of operational risk: 'operational risk management is about internal controls, not about quantification and capitalisation'; the quantification of operational risk is just one tool for controlling it (Cagan, 2001). Indeed, 'given the difficulty of quantifying aspects of operational risk, the reliance on a single number may itself be an operational risk' (Wilson, 2001). Ernst \& Young (2001) push the point further, developing the links between Basel 2 and corporate governance ideals, making operational risk a dimension of senior managerial attention to systems of internal control.

From the pragmatists' point of view, operational risk management is constructed as the management of risk management, a higher order governance function standing in a hierarchical relation to the calculative idealism of market and credit risk management functions.

Accordingly, operational risk embodies tensions between different forms of quantitative expertise in organisations and becomes a stake in the competition for pre-

\footnotetext{
${ }^{9}$ An article by the risk officer at Enron had the title 'Aiming for a single metric' (Buy, 2001).
} 
eminence in management hierarchies. Calculative pragmatists and idealists both articulate programmatic affinities between operational risk and ERM, but in different ways and emphasising different parts of Basel 2 (Rouyer, 2002). For the former, it is management systems and senior management oversight which provide the key basis for integrating different risk silos, with quantification as a support for this. For the latter, rational integration is achieved primarily by calculative means alone (eg, Doherty, 2000: 10-13), for example by systems for RAROC calculations.

Basel 2 embodies an explicit philosophy of relying on 'solid management processes' (Pillar 2) seeking to activate senior management responsibility for the self-assessment of risk, ie, the 'management of risk management', a feature which plays to the pragmatists' emphasis. However, both pragmatists and idealists are also united in a shared distrust of supervisor discretion, either through judgements about the quality of internal controls in the second pillar, or in supervisor use of a mysterious 'gamma' term (subsequently withdrawn) to modify banks' own calculations of economic capital.

To summarise: practitioner debates about operational risk refer extensively to issues of quantification, but not in a homogenous and consistent manner. Calculative idealism sees managing operational risk as no different in principle from market risk or credit risk, and it should therefore be accommodated within these frameworks. Calculative pragmatism accepts much of the idealists' need to model where this is possible, but places greater emphasis on management processes and internal controls as the key foundation of operational risk management. Although these ideal types rarely appear in pure form, their differences continue to surface in policy discussions about Basel 2 and in variations in the approaches adopted by particular banks. The tension between calculative pragmatism and idealism, also reflects in part, a collision between the disciplines of auditing and finance, the one a humble and pragmatic craft, despite a history of scientific pretensions, and the other drawing upon advanced mathematical techniques to model 'market' and 'credit' risks. ${ }^{10}$ So, operational risk embeds important differences within notions of economic calculation, differences which can be related to competing visions of the position of expertise in management hierarchies.

\section{Conclusion: the operational risk constellation}

The category of operational risk has been successfully institutionalised as a key feature of the Basel 2 banking regulation reforms. The concept is neither a discrete category, nor a set of well-defined practices but marks the potential for a new organisation of management knowledge, a 'constellation' (Burchell et al, 1985) or assembly in which multiple elements combine to create a new hybrid regulatory and managerial practice. New organisational experts and power relations around risk officers are coming into being around operational risk. Loose associations of experts are reinventing themselves in its name and there is a promise of a higher order discipline for the humbler end of risk management.

\footnotetext{
${ }^{10}$ For the purposes of this contrast, I include legal disciplines in auditing, since the notion of legal risk audit plays a key role in the emergence of legal risk management ideas under the operational risk umbrella.
} 
Operational risk is a meeting place, a passage point, a site of problematisation for apparently disparate concerns with fraud, processing error, business discontinuity, human resource management, legal liability as well as reputational and strategic risk management concerns. It is also a point where the capital charging framework runs up against its limits and overlaps with corporate governance issues. Basel 2 can be understood as a particular expression of a general climate of regulatory attention to organisational internal control systems and cultures of control. But it is also a regulatory programme on the grandest of scales, projecting an ideal, a fantasy perhaps (cf Clarke, 1999) of hyper-rational management for the global banking system. The proposals have been criticised for their needless complexity; for example, Goodhart (2001) argues that the Basel Committee should have been explicit about wanting an add-on factor for operational risks for systemic risk management purposes. But equally the rise of operational risk is an instructive case study for policy-makers; regulators should actively seek to create constellations of interest via concepts with wide appeal. Concepts themselves can be powerful technologies of change, as the example of operational risk shows.

The story of operational risk is still unfolding and this paper has sought to identify three key areas or fronts of development for the management of operational risk; definitional, data-gathering and calculative strategies. The proposals have invented new visibilities within risk management and new possibilities for intervention and control in the name of risk. This is not simply a process of technical innovation, but also the invention of new concepts of practice and new modes of argumentation. These definitional struggles, data collection paradoxes and competing calculative ambitions are embedded in a new intra-organisational politics, in which competition for buy-in, the allocation of responsibility and professional status are strategic stakes for internal agents, such as risk officers. 


\section{References}

Abbott, A. (1998) The System of Professions. Chicago: University of Chicago Press.

Ayres, I. and Braithwaite, J. (1992) Responsive Regulation: Transcending the Deregulation Debate. Oxford: Oxford University Press.

Basel Committee on Banking Supervision (2003a) The New Basel Capital Accord Third Consultative Paper. Bank for International Settlements, Basel, December.

Basel Committee on Banking Supervision (2003b) Quantitative Impact Study 3 Overview of Global Results. Bank for International Settlements, Basel, December.

Basel Committee on Banking Supervision (2001a) Consultative Document: Operational Risk. Bank for International Settlements, Basel, January.

Basel Committee on Banking Supervision (2001b) Sound Practices for the Management and Supervision of Operational Risk. Bank for International Settlements, Basel, December.

Basel Committee on Banking Supervision (1998a) Framework for the Evaluation of Internal Control. Bank for International Settlements, Basel, January.

Basel Committee on Banking Supervision (1998b) Operational Risk Management Survey. Bank for International Settlements, Basel, September.

BBA, ISDA and RMA (1999) Operational Risk: The Next Frontier. London: British Bankers Association, December.

Bourdieu, P. (1992) The Logic of Practice. Cambridge: Polity Press.

Burchell, S., Clubb, C. and Hopwood, A. (1985) 'Accounting in its Social Context: Towards a History of Value Added in the UK', Accounting, Organizations and Society, 10 (4): 381-413.

Buy, R. (2001) 'Aiming for a Single Metric', Erisk.com, February.

COSO (1991) Internal Control: Integrated Framework. Committee of Sponsoring Organizations of the Treadway Commission.

Cagan, P. (2001) 'Standard Operating Procedures', Erisk.com, March.

Calomiris, C. and Herring, R. (2002) 'The Regulation of Operational Risk in Investment Management Companies', Perspective, 8 (2): 1-19.

Clarke, L. (1999) Mission Improbable. Chicago: University of Chicago Press.

Ernst \& Young (2001). Basel - a better use of control (Operational Risk Management promotional brochure). 
Doherty, N. (2000) Integrated Risk Management. New York: McGraw-Hill.

Douglas, M. (1992) 'Risk and Blame', in M. Douglas (ed.) Risk and Blame: Essays In Cultural Theory. London: Routledge.

Gigerenzer, G. (2002) Reckoning with Risk: Learning to Live with Uncertainty. London: Penguin.

Goodhart, C. (2001) 'Operational Risk’, Special Paper 131, Financial Markets Group, London: London School of Economics.

Hoffman, D.G. (2002) Managing Operational Risk: 20 Firm-Wide Best Practice Strategies.

Hood, C., Rothstein, H. and Baldwin, R. (2001) The Government of Risk: Understanding Risk Regulation Regimes. Oxford: Oxford University Press.

ICAEW (1999) Internal Control: Guidance for the Directors of Listed Companies. London: Institute of Chartered Accountants in England and Wales.

Jameson, R. (2001a) 'Between RAROC and a hard place', Erisk.com, February.

Jameson, R. (2001b) 'Operational risk charges: a bad case of mission creep?' Erisk.com, May.

Jorion, P. (2001) Value at Risk. New York: McGraw-Hill.

Luhmann, N. (1992) Risk: A Sociological Theory. Berlin: de Gruyter.

Mackenzie, D. (2002) 'Models, Risk And Crises: The Global Financial System in 1998 and 2001', paper presented at the Organisational Encounters with Risk workshop, London School of Economics, May.

Moran, M. (1989) The Politics of the Financial Services Revolution: The USA, UK and Japan. London, Macmillan.

Moran, M. (1986) The Politics of Banking. London: Macmillan.

Porter, T. (1994) Trust in Numbers. Princeton: Princeton University Press.

Power, M. (2000) 'The New Risk Management', European Business Forum, 1 (1): 20.

Rose, N. and Miller, P. (1992) 'Political Power Beyond the State: Problematics of Government', British Journal of Sociology, 43 (2): 173-205.

Rouyer, S. (2002) 'Enterprise Risk Management for Financial Institutions', Erisk.com, January. 
Sieber, S. (1981) Fatal Remedies: The Ironies of Social Intervention. New York: Plenum Press.

Simons, R. (1999), 'How Risky is Your Company?', Harvard Business Review, MayJune.

Tribe, K. (1978) Land, Labour and Economic Discourse. London: Routledge.

Vaughan, D. (2002) 'Organizational Rituals of Risk and Error,' paper presented at the Organisational Encounters with Risk workshop, London School of Economics, May.

Vieten, H. (1996) Banking Regulation in Britain and Germany Compared: Capital Ratios, External Audit and Internal Control, PhD thesis, London University.

Wilson, D. (2001) 'Operational Risk' in L. Borodovsky and M. Lore (eds.) The Professional's Handbook of Financial Risk Management. Oxford: ButterworthHeinemann.

Wilson, D. (1995) 'VAR in Operation', $\underline{\text { Risk, }}$ December.

Wynne, B (2003) 'Is Environmental Risk a Cinderella Issue?' paper presented at the NIESR/ESRC joint workshop, January 16. 
- Mapping the Contours of

Contemporary Financial Services

Regulation

Julia Black
DP 17
- $\quad$ Reforming the UK Flood Insurance

Regime. The Breakdown of a

Gentlemen's Agreement

Michael Huber

- Perceptions of Risk: an experimental approach using internet questionnaires Frank A. Cowell and Guillermo Cruces

DP 18

\section{Available now in print or from http://www.lse.ac.uk/collections/CARR/documents/Default.htm}

- The Invention of Operational Risk Michael Power DP 16

- Precautionary Bans or Sacrificial Lambs? Participative Risk Regulation and the Reform of the UK Food Safety Regime

Henry Rothstein

DP 15

- Incentives, Choice and Accountability in the Provision of Public Services Timothy Besley and Maitreesh Ghatak

- $\quad$ Regulating Parliament: the regulatory state within Westminster Robert Kaye

- Business History and Risk

Terry Gourvish

Business Risk and Antitrust: comparative perspectives

Tony Freyer

The Risks of Working and the Risks of Not Working: historical perspectives on employers, workers, and occupational illness Joseph Melling

- The Open Method of Co-ordination and the European Welfare State Damian Chalmers and Martin Lodge

- Drivers and Drawbacks: regulation and environmental risk management systems

Marius Aalders

- Conceptualising Insurance: risk management under conditions of solvency

Michael Huber
- Social Licence and Environmental Protection: why businesses go beyond compliance

Neil Gunningham, Robert Kagan and Dorothy Thorton

- Neglected Risk Regulation: the institutional attenuation phenomenon Henry Rothstein

- Mass Media and Political Accountability Tim Besley, Robin Burgess and Andrea Pratt

- Embedding Regulatory Autonomy: the reform of Jamaican telecommunications regulation 19882001 Lindsay Stirton and Martin Lodge DP 5

- Critical Reflections on Regulation Julia Black

- The New Politics of Risk Regulation in Europe David Vogel

- The EU Commission and National Governments as Partners: EC regulatory expansion in telecommunications 1979-2000 Mark Thatcher

- $\quad$ Regulating Government in a 'Managerial' Age: towards a crossnational perspective Christopher Hood and Colin Scott DP 1

- Is Regulation Right?

Robert Baldwin

Business Risk Management in Government: pitfalls and possibilities Christopher Hood and Henry Rothstein Risk Management and Business Regulation Bridget Hutter and Michael Power DP 0 